\title{
Generalization of parameters in the storage-discharge relation for a low flow based on the hydrological analysis of sensitivity
}

\author{
K. Fujimura ${ }^{1}$, Y. Iseri ${ }^{2}$, S. Kanae ${ }^{2}$, and M. Murakami ${ }^{3}$ \\ ${ }^{1}$ School of Science and Engineering, Meisei University, Tokyo, Japan \\ ${ }^{2}$ Department of Civil Engineering, Graduate School of Engineering, Tokyo Institute of Technology, \\ Tokyo, Japan \\ ${ }^{3}$ School of Environmental Science and Engineering, Kochi University of Technology, Kochi, Japan \\ Correspondence to: K. Fujimura (fujimura@ar.meisei-u.ac.jp)
}

Received: 11 March 2015 - Accepted: 11 March 2015 - Published: 12 June 2015

\begin{abstract}
The storage-discharge relations have been widely used for water resource management and have led to reliable estimation of the impact of climate change on water resources. In a previous study, we carried out a sensitivity analysis of the parameters in a discharge-storage relation in the form of a power function and found that the optimum parameters can be characterized by an exponential function (Fujimura et al., 2014). The aim of this study is to extend the previous study to clarify the properties of the parameters in the storage-discharge relations by carrying out a sensitivity analysis of efficiency using a hydrological model. The study basins are four mountainous basins in Japan with different climates and geologies. The results confirm that the two parameters in the storage-discharge relations can be expressed in an inversely proportional relationship. In addition, we can conveniently assume a practical function for the storage-discharge relations where only one parameter is used on the basis of the new relationship between the two parameters.
\end{abstract}

\section{Introduction}

Low flow has been studied for more than 100 years because it is the basis of water resources that play a significant role in society through, for example, agricultural, industrial, and urban activities. The accurate estimation of low flow can contribute to better water resource management in the present, and in the future, more reliable evaluation of the impact of climate change on water resources. Hall (1968) reviewed the early studies on low flow, in which Horton (1936) had suggested that the nonlinearity of the discharge $Q$ with respect to the storage $S$ can be expressed by the general power function

$Q=K S^{N}$,

where $K$ is a constant and $N$ is the storage exponent treated as a parameter.

Although the storage-discharge relations for groundwater runoff from unconfined aquifers have been treated as secondorder polynomial functions on the basis of the hydraulic in- vestigation by Ding (1966), a general power function was introduced into the unit hydrograph model for overland flow and the parameters $K$ and $N$ were calibrated by Ding (2011). The general power function of the storage-discharge relation is written as

$Q=K^{N} S^{N}$

According to recent studies, the value of the exponent $N$ is varied between 1 and 3 or higher by calibration (e.g., Wittenberg, 1994 and Ding, 2011); however, it is currently unclear whether the optimum values of $N$ and $K$ follow a rule.

Fujimura et al. (2014) applied the general power function, Eq. (2), for low flows in mountainous basins over a period spanning more than 10 years using hourly data, and carried out sensitivity analysis using a hydrological model for 19900 sets of the two parameters $K$ and $N$, in which the exponent $N$ was varied between 1 and 100 in steps of 0.5 . The results showed that the optimum relation between $N$ and $K$ could 


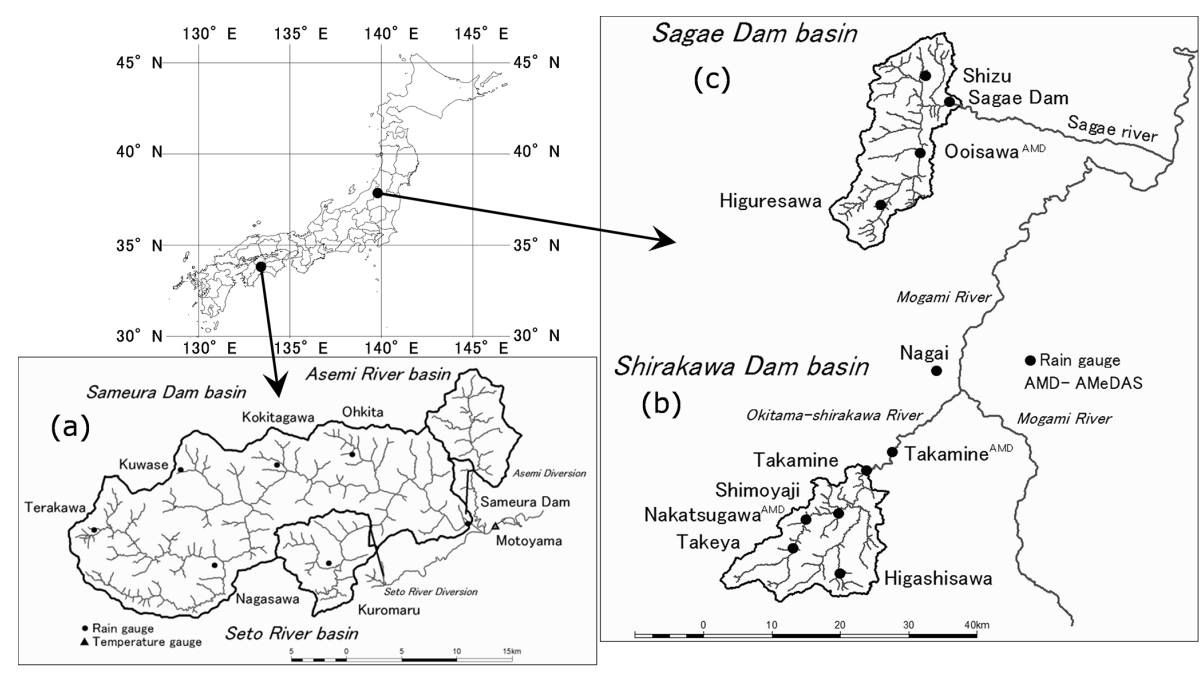

Figure 1. Locations of the four study basins: (a) Sameura Dam basin and Seto River basin within the Sameura Dam basin; (b) Shirakawa Dam basin; and (c) Sagae Dam basin.

be characterized by the following exponential function:

$K=\frac{1}{\alpha N^{\beta}}$,

where $\alpha$ and $\beta$ are constants. Moreover, the lowest error in the sensitivity analysis was obtained when $N$ was 100 .

The aim of this study is to extend the previous study to clarify the properties of the two-parameter $K-N$ relations by means of a sensitivity analysis of efficiency in which the exponent $N$ is varied between 1 and 100000 , which is in the neighborhood of the exponential function, Eq. (3), using a hydrological model, for four mountainous basins in Japan with different climates and geologies. Furthermore, we present a practical equation for the storage-discharge relations by assuming $N$ to be 100 for convenience of considering accuracy of simulations.

\section{Study basins, data and model}

The study basins are four mountainous basins located in western and eastern Japan with very different climates and geologies: the Sameura Dam basin $\left(472 \mathrm{~km}^{2}\right)$ and the Seto River basin $\left(53.7 \mathrm{~km}^{2}\right)$ within the Sameura Dam basin, which are located in the mountains of Shikoku and have variable rainfall, and the Shirakawa Dam basin $\left(206 \mathrm{~km}^{2}\right)$ and the Sagae Dam basin $\left(233 \mathrm{~km}^{2}\right)$, which are located in the Iide mountains in the Tohoku region and have heavy snowfall. The locations of the basins are shown in Fig. 1.

The topographies and geologies of the study basins are shown in Table 1. Because the basins are located in mountainous regions, the average elevations of basins are from ca. 700 to $900 \mathrm{~m}$. Geologically, Mesozoic metamorphic rock formations occupy most of the Sameura Dam basin, and Neogene volcanic rock formations are dominant in the Shi- rakawa Dam basin. The Sagae Dam basin has Mesozoic plutonic rock formations as well as Quaternary/Neogene volcanic rock formations.

Hourly rainfall data measured by the Ministry of Land, Infrastructure and Transport and the Automated Meteorological Data Acquisition System (AMeDAS) of Japan Meteorological Agency are used. The period of available hydrological data is 20 years from 1 January 1991 to 31 December 2010 for the Sameura Dam basin, 11 years from 1 October 2003 to 30 September 2014 for the Shirakawa dam basin, and 12 years from 1 October 2002 to 30 September 2014 for the Sagae Dam basin. Figure 2 shows the mean annual precipitation and runoff of each basin, in which the runoffs in the Shirakawa Dam basin and the Sagae Dam basin are higher than that of the Sameura Dam basin because of the volcanic rock formations and the snowy region. Because of the cold climate with heavy snowfall in the Shirakawa Dam basin and the Sagae Dam basin, rainfall data at some stations are not available in the winter season.

The daily hydrological model for a hilly or mountainous basin was proposed by Ando (1989), and subsequently, the model was modified by Fujimura et al. (2012) to cope with an hourly time scale. The hourly hydrological model used in this study mainly comprises three components: the DiskinNazimov rainfall infiltration model (Diskin and Nazimov, 1995, 1996), groundwater recharge and groundwater runoff calculations, and a direct runoff component that represents surface water storage within the basin. The basin was divided into a $500 \mathrm{~m}$ mesh, and at each grid the rainfall was estimated by an inverse distance weighting method using each rainfall gauge in the basin. Also at each grid, the infiltration rate and then the excess rainfall were calculated. A detailed explanation of the model and the calibration of the parameters, 
Table 1. Elevations and rock formations of study basins.

\begin{tabular}{llllllllll}
\hline \multirow{2}{*}{ Basin } & \multicolumn{3}{c}{ Elevation $(\mathrm{m})$} & & \multicolumn{5}{c}{ Geology: rock formation $(\%)$} \\
\cline { 2 - 3 } \cline { 8 - 10 } & Min. & Max. & Ave. & & Quaternary & Neogene & Paleozoic & Mesozoic & Total \\
\hline Sameura & 324 & 1880 & 910 & & 1.8 & 0.0 & 0.5 & 97.7 & 100.0 \\
Seto River & 369 & 1498 & 911 & & 0.9 & 0.0 & 0.0 & 99.1 & 100.0 \\
Shirakawa & 321 & 2029 & 697 & & 2.4 & 87.2 & 9.4 & 1.0 & 100.0 \\
Sagae & 280 & 1972 & 863 & & 14.4 & 32.4 & 2.9 & 50.3 & 100.0 \\
\hline
\end{tabular}

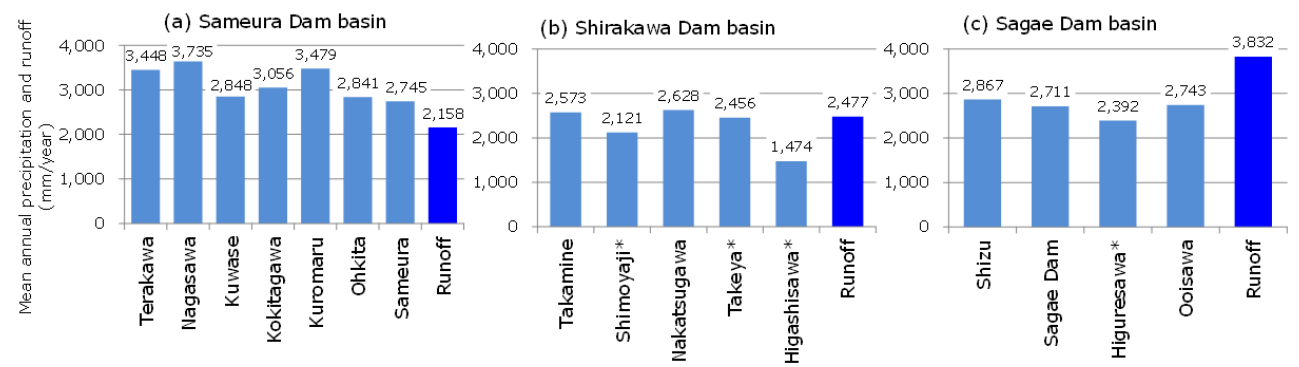

Figure 2. Mean annual precipitation and runoff of (a) Sameura Dam basin, (b) Shirakawa Dam basin, and (c) Sagae Dam basin. (* Data not available for winter season.)

except $K$ and $N$, have already been described in previous studies (Fujimura et al., 2001, 2012).

\section{Sensitivity analysis}

A sensitivity analysis is performed efficiently for six $N$ values in the range between 1 and 100000 , changing $K$ in a small range in the neighborhood of Eq. (3). Each simulation and the two parameters were assessed using the average daily runoff relative error (ADRE):

$\operatorname{ADRE}=\frac{\sum\left(\frac{\left|Q_{\mathrm{cal}}-Q_{\mathrm{obs}}\right|}{Q_{\mathrm{obs}}} \cdot 100\right)}{n}(\%)$,

where $Q_{\text {cal }}$ is the calculated mean daily total runoff, $Q_{\text {obs }}$ is the observed mean daily total runoff, and $n$ is the number of evaluated observations. The ADRE is focused on low flow between the 15th and 97th percentile of the flow duration curve of each basin.

The results of this sensitivity analysis are shown in Table 2, in which the first three columns shows the analysis conditions: the selected $N$, the range of values of $K$, and the step intervals for the simulation. The remaining columns show the obtained optimum values of $K$ and ADRE for each basin. The ADRE values are shown to five or six significant figures in order to distinguish the differences when the value of $N$ is higher. The ADRE curves with the $K$ ranges for each selected $N$ value are shown in Fig. 3a, and the relationship between the combination of optimum values of $N$ and $K$ to obtain the minimum ADRE is shown in the log-log graph in Fig. $3 \mathrm{~b}$ for the Sameura Dam basin. The plot of $\log K$ against $\log N$ with the minimum ADRE yields a straight line that is corresponds to Eq. (3), $K=1 /\left(\alpha N^{\beta}\right)$, in which the value of $\beta$ is 1.004 in the range of $N$ from 100 to 100000 . Table 3 summarizes the optimum values of $\alpha$ and $\beta$, and the correlation coefficient $R^{2}$ for the four study basins. The $\beta$ value can be assumed to be 1 because the $\beta$ values for all study basins are approximately 1 . Examples of the observed and simulated hydrographs obtained using the optimum values of $\alpha$ and $\beta(=1)$ are presented in Fig. 4 for the Sameura Dam basin (a) and the Shirakawa Dam basin (b). Figure 5 shows the observed and simulated flow duration curve for two selected case, the Sameura Dam basin (a) and the Shirakawa Dam basin (b). In all cases including these two cases, for low flow ( $>$ ca. 80th percentile), the simulated flow duration curve follows the observed one when using $N=100$ than $N=2$, which was ever used to.

\section{Discussion}

The $K-N$ relation, Eq. (3), is important for low flows of long periods when considering the optimum parameters in the storage-discharge Eq. (2). Assuming of $\beta=1$ in Eq. (3) leads to the following inversely proportional function:

$K=\frac{1}{\alpha N}$.

Although the optimum values of $N$ are high values between 100 and 100000, the ADRE values are almost the same for $N=100$ and 100000 , which means that we can adopt $N=100$ for practical purposes in engineering, such as water resource management. The value of 100 for $N$ might be 
Table 2. Analysis conditions and simulated optimum values of $K$ and ADRE for each basin.

\begin{tabular}{|c|c|c|c|c|c|c|c|c|c|c|}
\hline \multicolumn{3}{|c|}{ Analysis condition } & \multicolumn{2}{|c|}{ Sameura basin } & \multicolumn{2}{|c|}{ Seto River basin } & \multicolumn{2}{|c|}{ Shirakawa basin } & \multicolumn{2}{|c|}{ Sagae basin } \\
\hline$N$ & $K$ range & $K$ step & Opt. $K$ & ADRE & Opt. $K$ & ADRE & Opt. $K$ & ADRE & Opt. $K$ & ADRE \\
\hline 1 & $0.06-0.30$ & 0.01 & 0.12 & 48.971 & 0.055 & 78.586 & 0.082 & 41.049 & 0.052 & 31.253 \\
\hline 2 & $0.015-0.064$ & 0.001 & 0.031 & 38.625 & 0.014 & 74.293 & 0.021 & 38.096 & 0.011 & 30.065 \\
\hline 10 & $0.0020-0.0060$ & 0.0001 & 0.0034 & 32.294 & 0.0016 & 72.101 & 0.0027 & 36.304 & 0.0012 & 28.955 \\
\hline 100 & $0.00016-0.00064$ & 0.00001 & 0.00031 & 31.214 & 0.00014 & 71.828 & 0.00025 & 35.933 & 0.00011 & 28.684 \\
\hline $10^{3}$ & $1.6 \times 10^{5}-5.5 \times 10^{5}$ & $1.0 \times 10^{6}$ & $3.0 \times 10^{5}$ & 31.108 & $1.4 \times 10^{5}$ & 71.798 & $2.4 \times 10^{5}$ & 35.897 & $1.1 \times 10^{5}$ & 28.664 \\
\hline $10^{4}$ & $1.6 \times 10^{6}-6.5 \times 10^{6}$ & $1.0 \times 10^{7}$ & $3.0 \times 10^{6}$ & 31.098 & $1.4 \times 10^{6}$ & 71.7954 & $2.4 \times 10^{6}$ & 35.8936 & $1.1 \times 10^{6}$ & 28.662 \\
\hline $10^{5}$ & $1.6 \times 10^{7}-5.5 \times 10^{7}$ & $1.0 \times 10^{8}$ & $3.0 \times 10^{7}$ & 31.097 & $1.4 \times 10^{7}$ & 71.7951 & $2.4 \times 10^{7}$ & 35.8933 & $1.1 \times 10^{7}$ & 28.661 \\
\hline
\end{tabular}
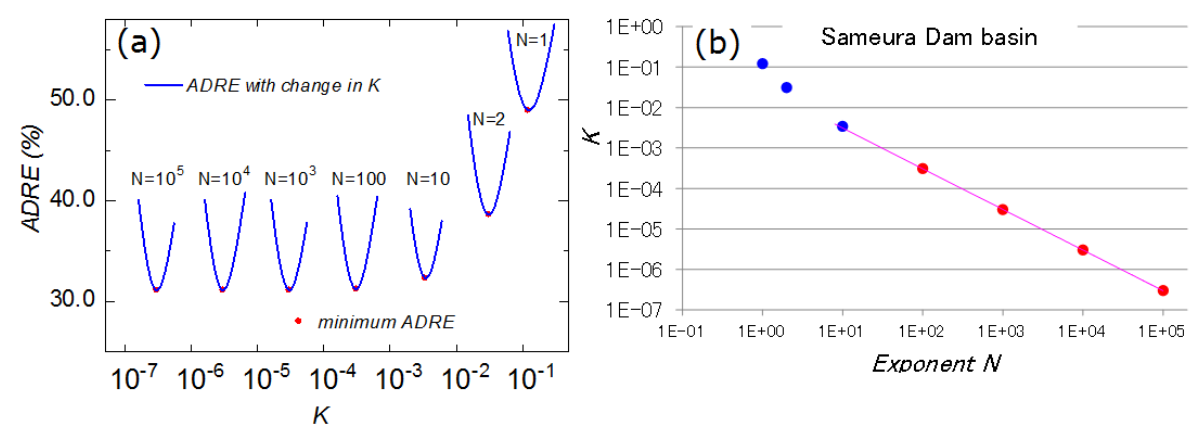

Figure 3. Relationship between $K$ and minimum ADRE (a), and relationship between exponent $N$ and constant $K$ in the log-log graph (b) for the Sameura Dam basin.

Table 3. Optimum values of parameters $\alpha$ and $\beta$, and the correlation coefficient $R^{2}$.

\begin{tabular}{lcccc}
\hline Basin & $\begin{array}{c}\text { Sameura } \\
\text { Dam }\end{array}$ & $\begin{array}{c}\text { Seto } \\
\text { River }\end{array}$ & $\begin{array}{c}\text { Shirakawa } \\
\text { Dam }\end{array}$ & $\begin{array}{c}\text { Sagae } \\
\text { Dam }\end{array}$ \\
\hline$\alpha$ & 31.9 & 71.4 & 39.5 & 90.9 \\
$\beta$ & 1.004 & 1 & 1.005 & 1 \\
$R^{2}$ & 1 & 1 & 1 & 1 \\
\hline
\end{tabular}

extremely high compared with those in the previous studies (Ding, 2011; Wittenberg, 1994, etc.), possibly because low flows cause natural complex phenomena to cumulate in wide basins during long periods (Smakhtin, 2001). Substituting $N=100$ into Eq. (5) for practical use leads to the following simplified equation:

$K=\frac{1}{100 \alpha}$.

Using these results, the storage-discharge relations given by Eq. (2) can be rewritten in the following form:

$Q=\left(\frac{S}{100 \alpha}\right)^{100}$

Comparison of Eqs. (2) and (7) reveals that Eq. (7) has one less parameter and may be applicable to practical use. However, in future work, the parameter $\alpha$ in Eq. (7) should be

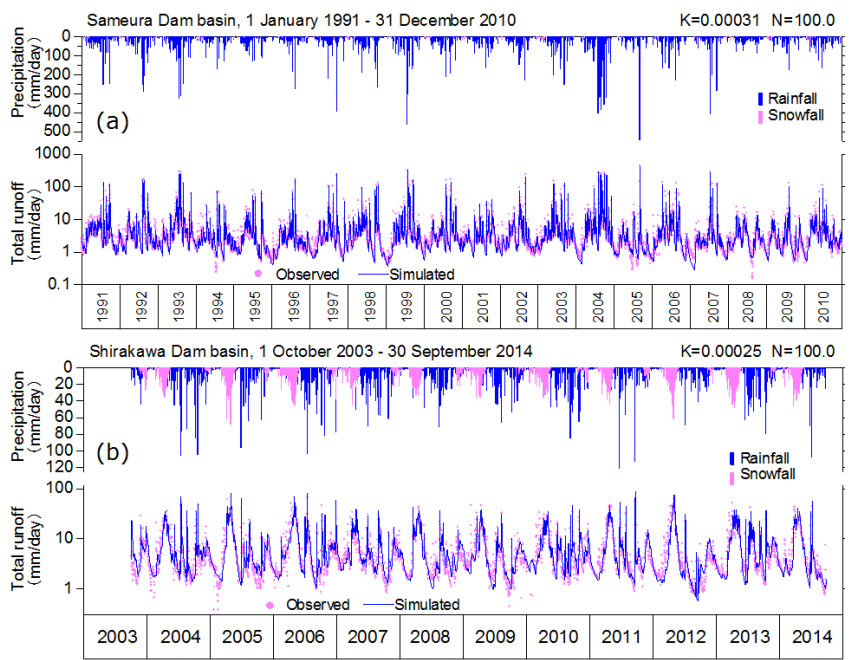

Figure 4. Examples of the observed and simulated hydrographs for the Sameura Dam basin (a) and the Shirakawa Dam basin (b).

investigated and determined specifically for each basin. Although the hydrological model used in this study would have uncertainties in the other parameters of the model and in the condition of calculation, i.e., the time step, the approach of this study is crucial for optimizing the parameters in the storage-discharge relations to improve the estimation of low flows. 

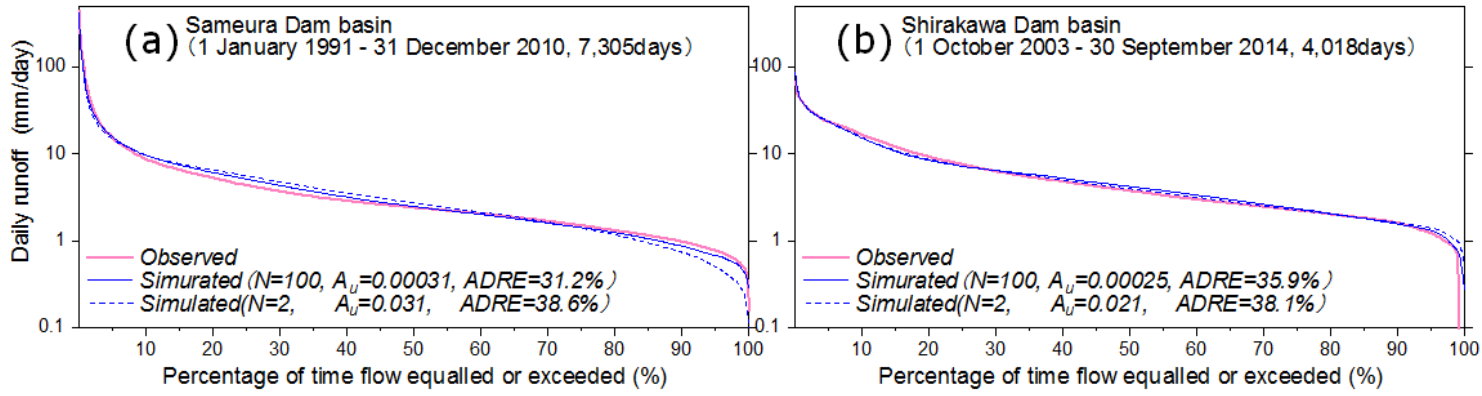

Figure 5. Examples of the observed and simulated flow duration curves for the Sameura Dam basin (a) and the Shirakawa Dam basin (b).

\section{Conclusions}

The sensitivity analysis of efficiency for four mountainous basins during long periods was performed for six $N$ values in the range of $1-100000$. The result showed that parameter $\beta$ equalled 1; therefore, the $K-N$ relations were represented by an inversely proportional equation when the value of $N$ is higher, such as more than 100 . In addition, the storagedischarge relations were presented as a simplified equation using the new $K-N$ relations, and it was suggested that the equations may be applicable for practical use in engineering, such as water resource management, at the present and in the future. The problem of investigating and specifying one parameter, $\alpha$, for each basin remains.

Acknowledgements. The authors wish to express their sincere gratitude to Ikeda Dam Control and Management Office of Japan Water Agency for providing rainfall and dam inflow data. This work was supported by a Grant-in-Aid for Scientific Research (C) KAKENHI (Grant Number 15K06241) from Japan Society for the Promotion of Science (JSPS).

\section{References}

Ando, Y.: Modelling of hydrological processes for a mountainous basin, in: New Directions for Surface Water Modeling, IAHS Publ., 181, 143-147, 1989.

Ding, J. Y.: Discussion of "Inflow hydrographs from large unconfined aquifers" by Ibrahim, H. A. and Brutsaert, W., J. Irr. Drain. Div.-ASCE, 92, 104-107, 1966.

Ding, J. Y.: A measure of watershed nonlinearity: interpreting a variable instantaneous unit hydrograph model on two vastly different sized watersheds, Hydrol. Earth Syst. Sci., 15, 405-423, doi:10.5194/hess-15-405-2011, 2011.

Diskin, M. H. and Nazimov, N.: Linear reservoir with feedback regulated inlet as a model for the infiltration process, J. Hydrol., 172, 313-330, 1995.

Diskin, M. H. and Nazimov, N.: Ponding time and infiltration capacity variation during steady rainfall, J. Hydrol., 178, 369-380, 1996.

Hall, F. R.: Base flow recessions - a review, Water Resour. Res., 4, 973-983, 1968.

Horton, R. E.: Natural stream channel-storage, EOS T. Am. Geophys. Un., 17, 406-415, 1936.

Fujimura, K. and Ando, Y.: Analysis of Infiltration Capacity in Upper Soil Layer during Unsteady Rainfall Using a Rainfall Simulator, Urban Drainage Modeling, 83-88, doi:10.1061/40583(275)9, 2001.

Fujimura, K., Shiraha, K., Kanae, S., and Murakami, M.: Development of the hourly hydrological model for mountainous basins using the storage function method and the Diskin-Nazimov infiltration model, in: Models - Repositories of Knowledge, IAHS Publ., 355, 338-344, 2012.

Fujimura, Y., Iseri, K., Kanae, S., and Murakami, M.: Identification of low-flow parameters using hydrological model in selected mountainous basins in Japan, in: Evolving Water Resources Systems: Understanding, Predicting and Managing Water-Society Interactions, IAHS Publ., 364, 51-56, 2014.

Smakhtin, V. U.: Low flow hydrology: a review, J. Hydrol., 240, 147-186, 2001.

Wittenberg, H.: Nonlinear analysis of low flow recession curves, IAHS Publ., 221, 61-67, 1994. 